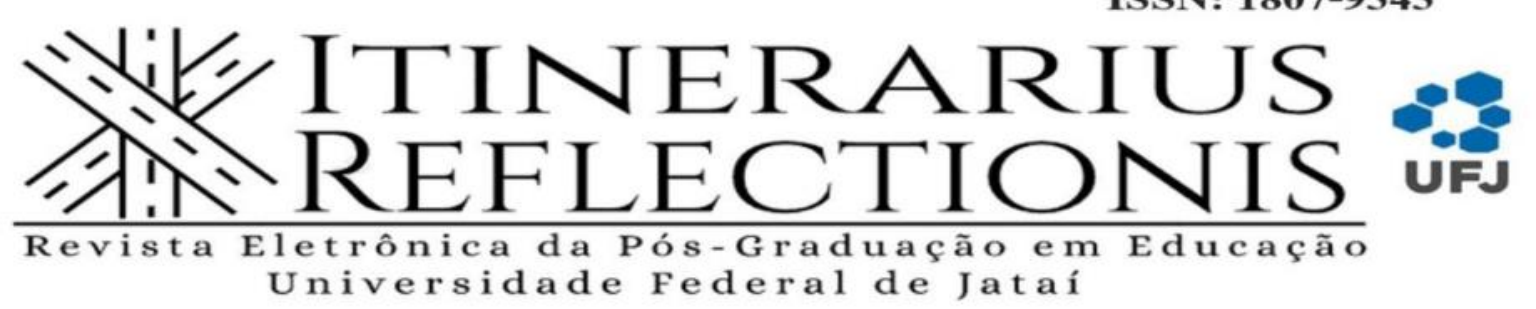

Volume, 17, n.4, ano 2021

\title{
Pluralidade familiar e Educação Infantil
}

\author{
Jeanne Yuriko Shintaku Ramos ${ }^{1}$ \\ Halline Mariana Santos Silva ${ }^{2}$ \\ José Sílvio de Oliveira ${ }^{3}$
}

\begin{abstract}
Resumo: O presente artigo é fruto de pesquisa científica de natureza teórica, cujos dados coletados são constituídos por pesquisa bibliográfica, versa sobre pluralidade familiar e educação infantil, logo, reflete sobre a construção histórica da instituição social família e a diversidade de constituição familiar, fazendo-se, por isso, necessário reconhecê-las no ambiente escolar, já que a educação trabalha com sujeitos sócio - historicamente situados. Apresentamos, assim, o conceito de infância, considerando questões históricas e as contradições sociais. Identificamos as contribuições da família para o desenvolvimento da criança, e a influência familiar no processo de aprendizagem. E concluímos que, apesar da pluralidade familiar, presente na sociedade atual, há resistência na aceitação de profissionais do sexo masculino na área da pedagogia, em relação à sua atuação e permanência na educação infantil.
\end{abstract}

Palavras-chave: Infância. Diversidade. Educação.

\section{Family plurality and Preschool Education}

Abstract: This article is the result of scientific research of a theoretical nature, whose collected data are constituted by bibliographic research, deals with family plurality and early preschool education, therefore, reflects on the historical construction of the family social institution and the diversity of family constitution, making it necessary to recognize them in the school environment, since education works with socio-social subjects - historically situated. Thus, we present the concept of childhood, considering historical issues and social contradictions. We identified the contributions of the family to the child's development, and the family influence in the learning process. And we conclude that, but the family plurality present in today's society, there is resistance in the acceptance of male professionals in the area of pedagogy, in relation to their performance and permanence in preschool education.

Keywords: Childhood. Diversity. Education.

\section{INTRODUÇÃO}

\footnotetext{
1 Auxiliar de atividades educativas da Prefeitura Municipal de Jataí/PMJ e formada em Pedagogia pela Universidade Federal de Jataí/UFJ, e-mail: Jeanne_yuriko@ discente.ufj.edu.br

${ }^{2}$ Doutora em Educação e docente do Curso de Pedagogia da UAE/EDU da Universidade Federal de Jataí/UFJ, email: hallinemariana@ufj.edu.br

${ }^{3}$ Doutor em Educação e docente do Curso de Pedagogia da UAE/EDU da Universidade Federal de Jataí/UFJ, email: js89083@ufj.edu.br
} 


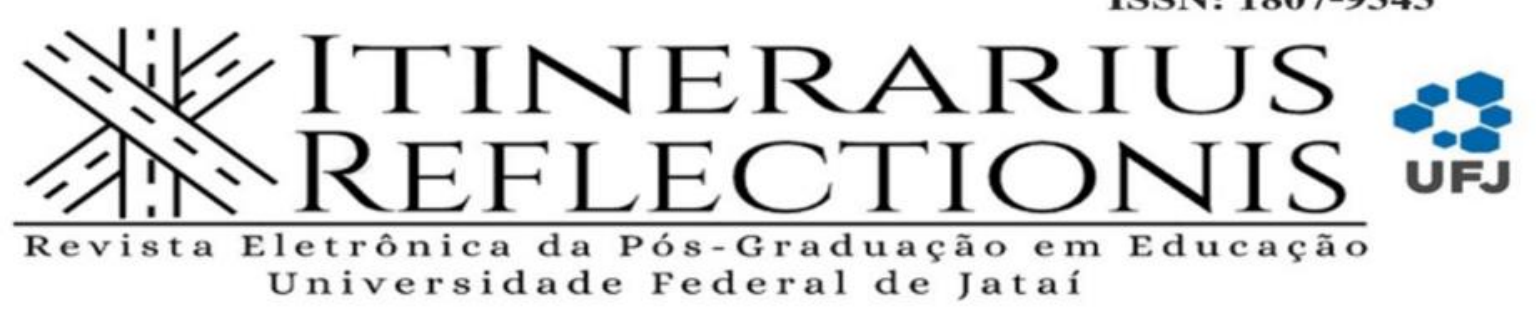

Volume, 17, número 3, ano 2021

Pesquisar e refletir a relação pluralidade familiar e educação infantil é, sem dúvida, indagar pelas diferenças advindas da formação docente dos educadores, monitores e auxiliares da educação, logo é uma questão primordial para a consolidação da pedagogia no que diz respeito às diferenças, preparando, assim, os profissionais para atuarem com a diversidade da constituição familiar que a realidade impõe bem como os seus desdobramentos, como é o caso do pedagogo do gênero masculino.

O interesse pela temática surge de nossa inserção profissional no campo da educação. Ainda hoje, no século XXI, há preconceito em relação à inserção de profissionais do sexo masculino no âmbito da educação infantil, isso decorre da resistência de muitos pais em aceitar profissionais do gênero masculino na educação infantil, ou seja, negam a diversidade no âmbito social e presente na escola. Nesta mesma direção, também existe a dificuldade do profissional em lidar com a pluralidade familiar que ele encontra durante a docência. Ou seja, a escola ainda não percebeu as mudanças sociais e históricas da sociedade e não levou para seu interior discussões sobre essa temática. Daí a pertinência deste tema.

Para a realização dessa reflexão, inicialmente buscamos em artigos e dissertações que abordam o tema, realizando levantamento bibliográfico exploratórios, o que nos fez perceber uma carência diante do assunto em comparação a tantos outros que apresentam vários estudos de diversos autores.

\section{O CONTEXTO HISTÓRICO E SOCIAL E A PLURALIDADE FAMILIAR}

Compreender as determinações historicamente constituídas sobre as categorias da família, infância e da educação em seu sentido diverso e plural, são fundamentais para nossa reflexão teórica. A origem da família está diretamente ligada à história da civilização, posto que surgiu como um fenômeno natural, fruto da necessidade de o ser humano estabelecer relações afetivas de forma estável. Noronha e Parron (2017) dizem que a família brasileira tem como base a sistematização formulada pelo direito romano e pelo direito canônico. Através do direito romano, por meio de suas normas, que a família brasileira foi estruturada. O que antes era instituído mediante os costumes, com a ausência do regimento jurídico, passa então a se basear 


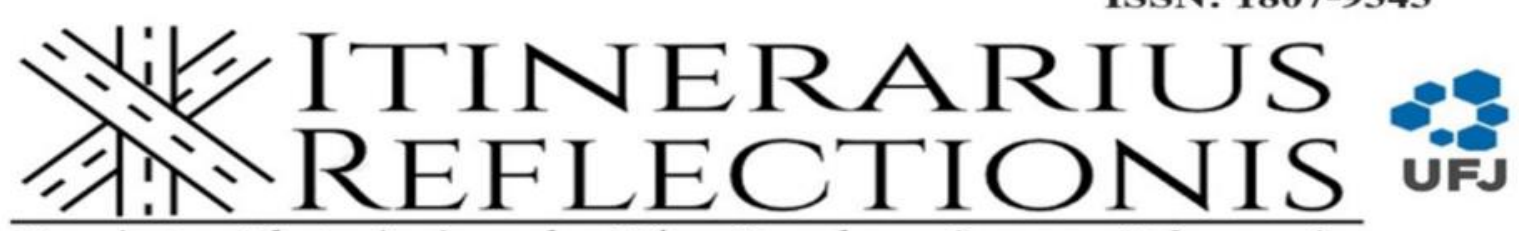

Revista Eletrônica da Pós-Graduação em Educação Universidade Federal de Jataí

Volume, 17, número 3, ano 2021

no casamento como ponto de início para a formação da família. Portanto, somente haveria família se houvesse casamento. Na época do Império, devido à ascensão do Cristianismo, apenas o casamento católico era reconhecido, o casamento que até então era a única forma de se iniciar uma família, passa a ser incumbência do Direito Canônico. Portanto, apenas casariam e formariam família, aqueles que professassem essa fé. Os autores explicam que entre o período de 1545 a 1563 a Igreja ainda era a única que detinha o privilégio legal perante o matrimônio, seguindo os ditames do Concílio de Trento de 1563 e das Constituições do Arcebispado da Bahia. Entretanto, em decorrência da imigração, que fez aumentar o índice de pessoas que tinham outras convicções religiosas, ou seja, aquelas que não seguiam o catolicismo e estavam impedidas de contraírem o matrimônio, o Estado intervém, criando o casamento misto, no qual era possível a união de pessoas pertencentes a seitas dissidentes.

Destarte, Noronha e Parron (2017) esclarecem que no Brasil, quando Colônia e Império, existiam três variáveis de casamentos: o casamento católico, casamento misto (católico e não católico) e o casamento entre pessoas de seitas diferentes. Em decorrência da chegada dos negros advindos da África, trazidos pelos portugueses em razão da escravidão, sucedeu uma intensa miscigenação cultural no país, fator este que não foi bem visto pela crença predominante. Apenas após metade do século XVIII, com a criação da Lei do Marquês de Pombal, que o casamento entre gentios e brancos foi permitido. Dessa maneira a família brasileira teve origem, de maneira híbrida, por diferentes povos e culturas, com forte pressão imposta pelas normas de cunho moral da igreja católica.

Aos poucos, a família que até então apenas era reconhecida como tal se seus princípios condissessem com o Direito Canônico, agora passa a ter um enfoque social com caráter produtivo, econômico e estrutura afetiva, sob o olhar do Estado, explicam Noronha e Parron (2017). Entretanto, ainda com forte influência da Igreja, que ainda assim, trazia conceitos interpretados de formas preconceituosas em relação a uniões de pessoas não católicas. Até 1988, o discurso era restrito, considerando como 'família' apenas aqueles que se uniam pelo matrimônio, apoiado pelo código civil de 1916. Nessa mesma linha de pensamento destacavase a Lei do Divórcio que imputava à parte culpada pela separação sanções com alusão ao casamento eterno. Com a promulgação da Constituição Federal de 1988, foram várias as inovações jurídicas, que refletiram diretamente no Direito de Famílias: a partir de então, a 


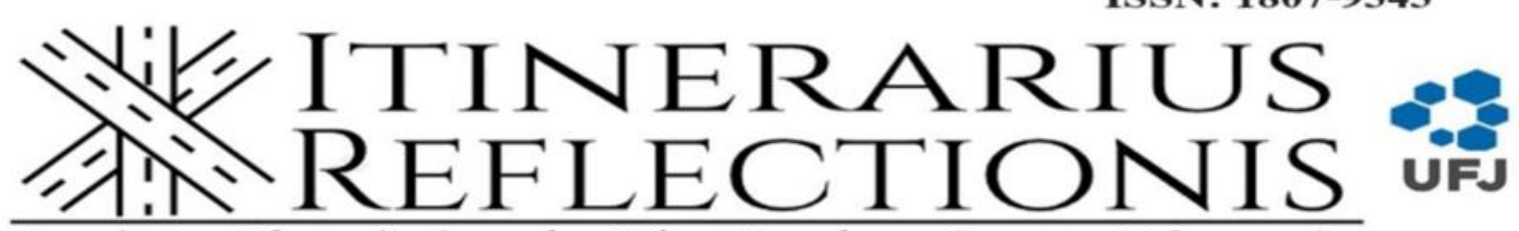

Revista Eletrônica da Pós-Graduação em Educação Universidade Federal de Jataí

Volume, 17, número 3, ano 2021

mulher que antes era vista e tratada com inferioridade, passa a ter direitos igualitários ao homem, assim como as crianças, independente da forma com que elas fossem concebidas. Outro destaque da Constituição refere-se ao divórcio, como modo de desfazer o casamento civil, assim como a conformidade quanto ao direito garantido à família, seja ela através do casamento, união estável ou as monoparentais. Além das mudanças conseguintes à Constituição, os autores ainda atribuem ao Supremo Tribunal Federal o mérito do reconhecimento das uniões entre homossexuais como formas de famílias, conferindo-lhes o direito à proteção do Estado, bem como os demais casais unidos pelo vínculo de união estável.

Contudo, pode-se dizer que a família do antigo código de 1916 compreendia uma concepção tradicional e monopolizada de família como sendo aquela relacionada apenas a núcleos ligados a enlaces sanguíneos, e por meio de matrimônio, com vertente económica, patrimonial e de reprodução, e a partir do Lex Fundamentallis de 1988 o conceito família passou a ser compreendido abarcando toda sua pluralidade, passando a constituir-se sob a vertente afetiva, embalada por princípios de ordem constitucional.

Observando o contexto histórico e social brasileiro, por meio da literatura pesquisada, constatamos que a pluralidade familiar se origina com a colonização dos portugueses, que trouxeram aos nativos o estilo de vida hierárquico para as famílias e o modelo patriarcal que perduram por décadas e pelas transformações que ocorreram nos meados do século XXI. A miscigenação da população refletiu na formação de famílias “com práticas de valores distintos, além do mais, devido à diferença de classes sociais (classe baixa, média e alta), os valores sociais também se tornaram diversificados" (LOBATO e SANTOS, s/d, p. 279). Os autores relatam que a miscigenação dos povos (índios, caboclo, negro e imigrantes) desencadeou na relação família-escola especificidades conjunturais. Percebe-se na década de 1920, na visão dos autores, muitas formas de concepção da família, que é influenciada por questões como o desemprego, religiosidade, valores éticos e morais, que moldam a formação da nova organização familiar. Dentro dessa nova configuração familiar, a mulher ganha um novo papel social, é percebida pela comunidade e pelo mercado de trabalho. Assim, compreendemos para fins dessa pesquisa, o conceito de família como sendo uma instituição social fundamental para compreender a natureza da sociedade, posto que nasceu de forma natural, fruto da necessidade de estabelecermos relações sociais afetivas. 


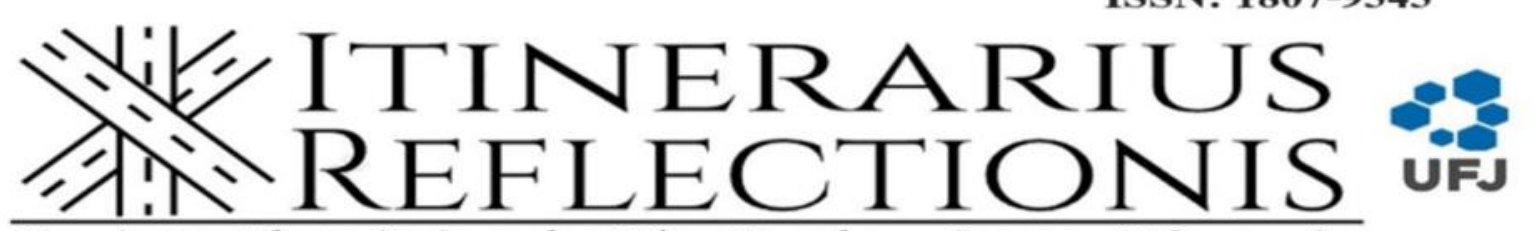

Revista Eletrônica da Pós-Graduação em Educação Universidade Federal de Jataí

Volume, 17, número 3, ano 2021

De acordo com os estudos de Lins, Silva, Lins e Carneiro (2014), o sentimento de infância, presente na sociedade moderna, nem sempre foi valorizado durante a idade média. Praticamente inexistia esse sentimento, fato que perdurou até o século XVIII. Nesse período, a criança logo que apresentasse algum desenvolvimento misturava-se ao mundo dos adultos, participando de atividades semelhantes, como festas, jogos e brincadeiras. Já no século XIX, inaugura-se uma visão de criança sem valor econômico, mas de valor emocional inquestionável, criando uma concepção de infância plenamente aceita no século XX. Até o século XVII, a ciência desconhecia a infância, não havia lugar para esta na sociedade, fato caracterizado pela inexistência de uma expressão particular a ela. Somente então, a partir das ideias e dos sentimentos de proteção, amparo, dependência, que surge a infância. Nesse período, nas classes dominantes, surgiu a primeira concepção real de infância, a partir da observação dos movimentos de dependência das crianças muito pequenas. $\mathrm{O}$ adulto passou, então, pouco a pouco, a preocupar-se com ela como um ser dependente e fraco.

Entretanto, nesse contexto, a criança era vista como irracional, como explica os estudos de Nascimento, Brancher e Oliveira (2008). Nessa época, a primeira preocupação com a infância ligou-se a uma rígida disciplina e à difusão da cultura existente, limitando todo e qualquer movimento infantil destinado ao prazer e ao aprendizado. Nesse período, era comum o incentivo aos pais a punição física de seus filhos, através de agressões com varas, chicotes entre outros. Portanto, as crianças passaram a ser vistas como seres biológicos, que necessitavam de cuidados e de disciplina para se transformarem em adultos.

A partir da influência dos estudos de Rousseau (1995), a criança começou a ser vista de maneira diferenciada de até então. O autor, considerado um dos primeiros pedagogos da história, propôs uma educação infantil sem juízes, sem prisões e sem exércitos. Nascimento et al. (2008) explicam que, a partir da Revolução Francesa, em 1789, modificou-se a função do Estado e, com isso, a responsabilidade para com a criança e o interesse por ela, os governos começaram então a se preocupar com o bem-estar e com a educação das crianças.

Ao conceder à criança um conjunto de características e atribuir à infância como uma fase do desenvolvimento humano, a ciência abre campo de estudo e investigação sobre esse grupo etário. De acordo com os estudos de Nascimento et al. (2008), Durkheim (1978) foi quem primeiro buscou entrelaçar os fios da infância aos fios da escola com objetivos de "moralizar" 


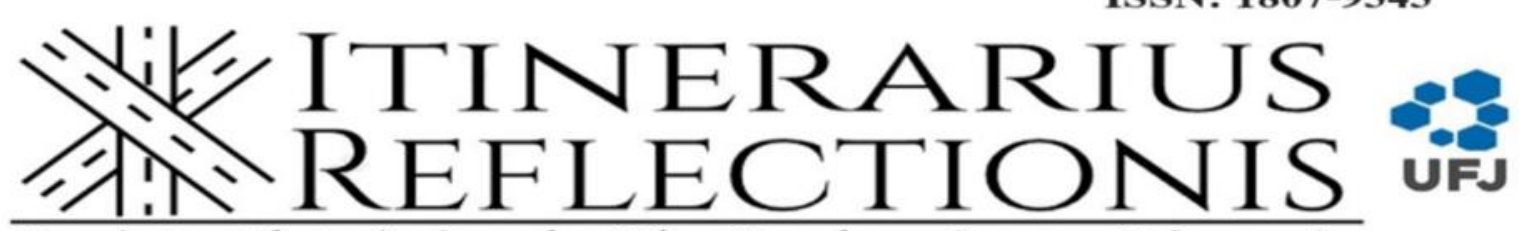

Revista Eletrônica da Pós-Graduação em Educação Universidade Federal de Jataí

Volume, 17, número 3, ano 2021

e disciplinar a criança. De acordo com as pesquisas de Emile Durkheim (1978), a criança, além de questionadora, passa de uma impressão para outra, de um sentimento para outro, com a mais extraordinária rapidez. Para controlar "os humores endoidecidos" das crianças, Durkheim (1978) propôs três elementos fundamentais na educação moral das novas gerações, as quais deverão ser capazes de se adequar às regras do jogo social, político e econômico: o espírito de disciplina, o espírito de abnegação (sacrificar suas vontades pessoais em nome do coletivo) e a autonomia da vontade.

Através da análise dos estudos existentes sobre a história da infância, podemos constatar que a preocupação com a criança se encontra presente somente a partir do século XIX, tanto no Brasil como em outros lugares do mundo. Portanto, a criança e a infância são compreendidas como categorias construídas historicamente. Nesta trajetória, diferentes significados foram constituídos em distintos contextos sociais.

Lins et al. (2014), ao citar Carvalho, (2008) explicam que no Brasil, com a Declaração de Independência, em 1822, fez-se necessária a criação de uma Constituição, que foi promulgada em 1824. Nesta, contudo, mantiveram-se as características do Brasil Colônia, como: trabalho escravo, dependência política do país em relação a Portugal e relações de poder centralizadas no domínio dos grandes proprietários e não havia nenhuma referência à infância ou a práticas relacionadas às crianças. Entretanto, neste contexto, intensificaram-se as intervenções médicas nas questões de saúde e higiene e, consequentemente, os cuidados dedicados à infância e à família. Diante do exposto, podemos evidenciar então que a maneira como a infância é vista atualmente é consequência de constantes transformações culturais pelas quais passamos enquanto sociedade, e que é de extrema importância nos darmos conta destas transformações para compreendermos a dimensão que a infância ocupa atualmente.

\subsection{A relação família, infância e Educação Infantil}

Analisando a interação entre as famílias e a instituição social educacional voltada ao atendimento da criança, e destacando como a família, a infância aparecem no texto de documentos legais e normativos voltados para a educação e para a criança. Identificamos que a Constituição da República Federativa do Brasil de 1988 é a lei fundamental e suprema da nação, referencial e parâmetro de validade a todas as demais espécies normativas, situando-se no topo 


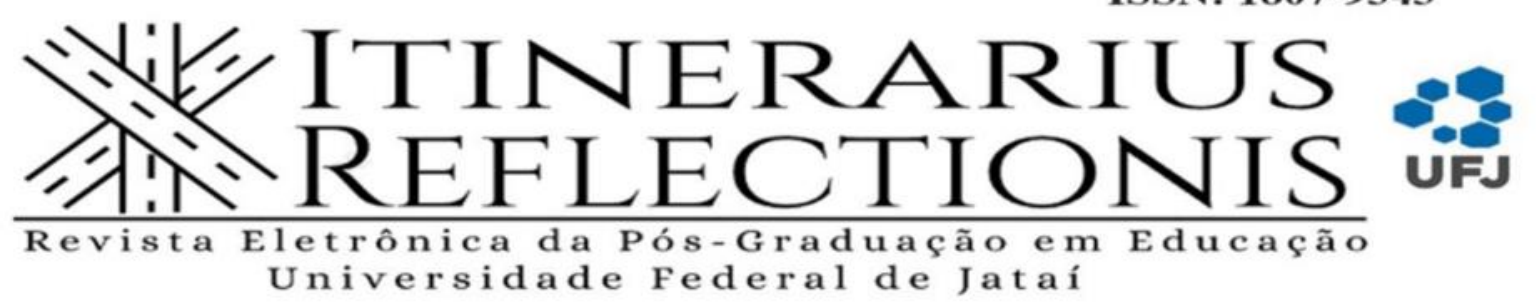

Volume, 17, número 3, ano 2021

do ordenamento jurídico. Foi aprovada pela Assembleia Nacional Constituinte em 22 de setembro de 1988 e promulgada em 5 de outubro de 1988. Ficou conhecida como "Constituição Cidadã", por ter sido concebida no processo de redemocratização, iniciado com o encerramento da ditadura militar no Brasil (1964 -1985). Por intermédio desta, foram asseguradas diversas garantias constitucionais, com o objetivo de dar maior efetividade aos direitos fundamentais, permitindo a participação do Poder Judiciário sempre que houver lesão ou ameaça de lesão a direitos.

O livro é dividido em nove títulos, dentre eles, o título VIII — Ordem Social: Do artigo 193 ao 232 são tratados os temas relacionados ao bom convívio e desenvolvimento social do cidadão, como deveres do Estado, a saber: seguridade social (saúde pública, previdência social e assistência social); educação, cultura e esporte; ciência e tecnologia; comunicação; meio ambiente e família (incluindo nesta acepção crianças, adolescentes e idosos); e população indígena. Dentro do título VIII- Da ordem social, destacamos na seção I - Da educação, exposto no capítulo III art. 205, onde a constituição assegura o direito à educação como benefício a todos e dever do Estado e da família, com intuito de alcançar o desenvolvimento pessoal e profissional dos cidadãos.

O livro também aponta a garantia da educação básica, obrigatória e gratuita dos quatro aos dezessete anos de idade, destacando no art. 208, inciso IV do mesmo capítulo acima referido, a segurança quanto à “[...] educação infantil, em creche e pré-escola, às crianças até 5 (cinco) anos de idade" (BRASIL 2016. p.124) Ressaltamos através do Capítulo VII - Da Família, da Criança, do Adolescente, do Jovem e do Idoso descrito na constituição que a família, como base integrante da sociedade, tem especial proteção do Estado garantida. Fica, portanto, deliberado que é dever da família, sociedade e Estado assegurar à criança quanto aos seus diretos à:vida, saúde, alimentação, educação lazer, profissionalização, cultura, dignidade, respeito, liberdade e a convivência familiar e comunitária, deixando-os ilesos de qualquer situação de negligência, discriminação, exploração, violência, crueldade e opressão.

A Lei de Diretrizes e Bases da Educação Nacional - LDB (BRASIL, 1996) afirma em seu Art. 29 que a educação infantil, primeira etapa da educação básica, tem como finalidade o desenvolvimento integral da criança de até 5 (cinco) anos, em seus aspectos físico, psicológico, intelectual e social, complementando a ação da família e da comunidade. A educação Infantil, 


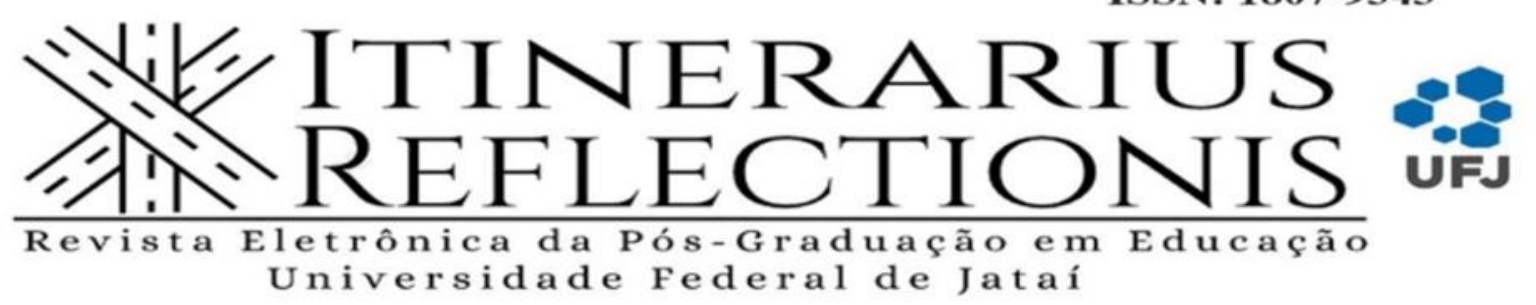

Volume, 17, número 3, ano 2021

como primeira etapa da educação básica, tem como objetivo principal promover as habilidades físicas, psicológicas, intelectuais e sociais das crianças de até cinco anos, juntamente com a família e comunidade. Será oferecida em creches ou em instituições correspondentes, para crianças de até três anos e em pré-escolas, para crianças de quatro a cinco anos de idade. As avaliações deverão ocorrer mediante acompanhamento e registro do desenvolvimento das crianças, sem o objetivo de promoção, mesmo para o acesso ao ensino fundamental, com a carga horária mínima de oitocentos horas distribuídas em no mínimo duzentos dias letivos. Para turno parcial, quatro horas no mínimo e sete horas para período integral, sendo que a criança deverá frequentar sessenta por cento do total de horas.

O Estatuto da Criança e do Adolescente (ECA) é o conjunto de normas do ordenamento jurídico brasileiro que tem como objetivo a proteção integral da criança e do adolescente. É o marco legal e regulatório dos direitos humanos de crianças e adolescentes. O ECA foi instituído pela Lei 8.069 em 13 de julho de 1990, que regulamenta os direitos das crianças e dos adolescentes, inspirado pelos projetos fornecidos pela Constituição Federal de 1988, adotando uma série de regras internacionais inspiradas na Convenção sobre os Direitos da Criança das Nações Unidas.

Considerado um divisor de águas no que diz respeito ao olhar para as crianças e adolescentes, o Estatuto divide-se em dois livros: o primeiro trata da proteção dos direitos fundamentais à pessoa em desenvolvimento, no qual crianças e adolescentes são vistos como sujeitos de direitos, e o segundo trata dos órgãos e procedimentos protetivos, reiterando a responsabilidade da família, sociedade e Estado de garantir as condições para o pleno desenvolvimento dessa população, colocando-a a salvo de toda forma de discriminação, exploração e violência. Assim, para o ECA é considerada criança a pessoa com idade inferior a doze anos e adolescente aquela entre doze e dezoito anos de idade.

A Constituição Federativa de 1988 e a Base Nacional Comum Curricular - BNCC (BRASIL, 2017) estabelecem o atendimento em creche e pré-escola às crianças de zero a 6 anos de idade como dever do Estado. Na LDB (BRASIL, 1996), a Educação Infantil é parte integrante da Educação Básica, situando-se no mesmo patamar que o Ensino Fundamental e o Ensino Médio. Em modificação introduzida na LDB no ano de 2006, o acesso ao Ensino 


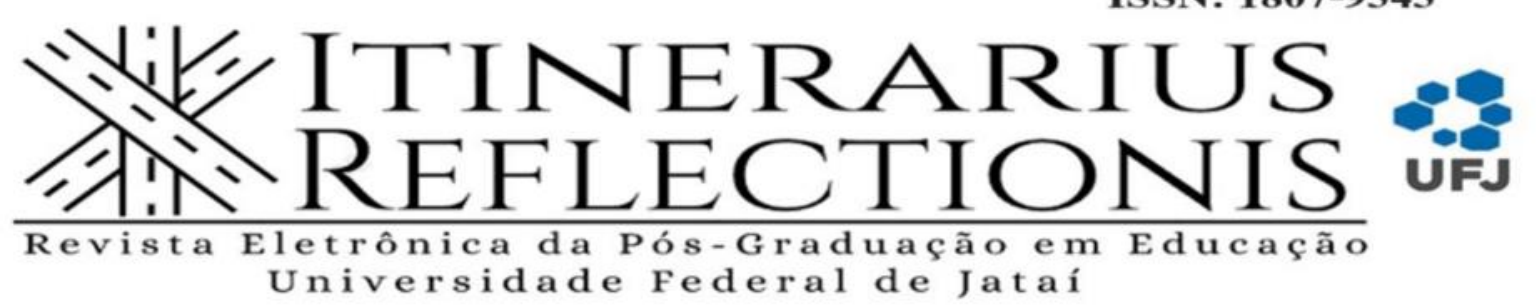

Volume, 17, número 3, ano 2021

Fundamental passou para os 6 anos de idade, cabendo à Educação Infantil o atendimento à faixa etária de zero a cinco anos.

Tendo em vista que as crianças, apesar de pequenas, já carregam consigo suas vivências e culturas, Vianna e Finco (2009), destacam o fato de que a vida social das crianças tem início na educação infantil, espaço onde elas vão ter e manter contato com outras crianças de diversos ciclos sociais, religiões e etnias, com valores diferentes, convivendo, assim, com a pluralidade social. O contexto histórico e social em que estamos inseridos, em decorrência da colonização e outros, nos deixaram a herança da diversidade de gênero, racial e social, e no ambiente escolar isso não se faz diferente. A partir desse entendimento tentaremos compreender como o tema da diversidade é tratado na $\mathrm{BNCC}$, documento oficial que rege o ensino básico brasileiro e apresenta propostas para o trabalho docente. Analisando as primeiras 53 páginas, que estão direcionadas à educação infantil, podemos perceber que o documento deixa lacunas quanto ao tema gênero, sexualidade e família e se dispõe a falar de forma superficial apenas sobre o tema diversidade.

Ao percorrer o texto da BNCC, a atenção à diversidade aparece nas competências gerais e também nos descritores dos componentes curriculares das disciplinas, tais como: na relação entre o eu, o outro e nós, em que se destaca "Atuar em grupo e demonstrar interesse em construir novas relações, respeitando a diversidade e solidarizando-se com os outros." (BRASIL, 2017, p. 50). As razões pelas quais o documento deixa de aprofundar, e até mesmo omite e ignora certos temas podem ser diversas, tais como pressão política e religiosa, ação que não apaga a complexidade da realidade que vivenciamos.

\subsection{Diversas famílias, diversas formas de interação entre pais e ambiente escolar}

Nascimento (2006), ao citar Ferrari e Kaloustian (1994), afirma que a família desempenha papel decisivo na educação formal e informal. Família compreende, assim, um núcleo primário onde os sujeitos fazem parte de um conjunto globalizado de intenções previamente socializadas: "Em seu espaço são absorvidos os valores éticos e humanitários, aprofundam-se os laços de solidariedade, constroem-se as marcas entre as gerações e são observados valores culturais" (p. 2). São diversas famílias, diversas formas de interação entre pais e ambiente escolar. Por volta dos anos de 1970, com a inserção da mulher no mercado de 


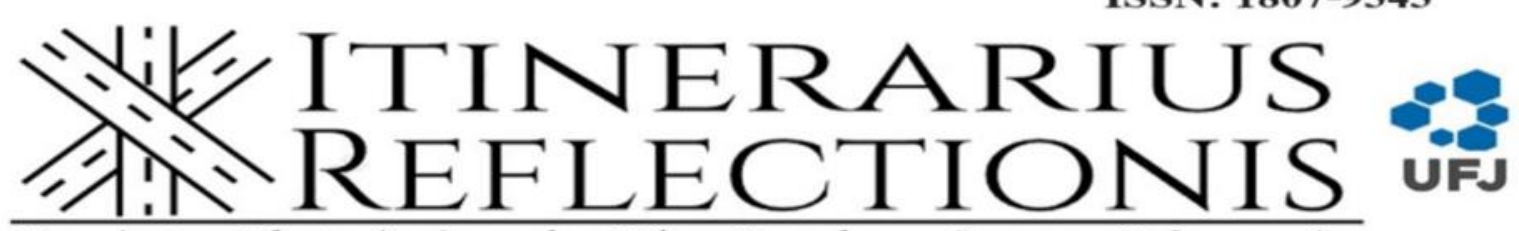

Revista Eletrônica da Pós-Graduação em Educação Universidade Federal de Jataí

Volume, 17, número 3, ano 2021

trabalho, houve um passo importante para novas configurações sociais. Diante da busca por sua independência, tem-se o início do movimento feminista, exigindo a criação da creche. Dessa forma, no início o direito à educação das crianças vincula ao direito trabalhista dos pais, onde nesse espaço da sociedade vivemos as mais diferentes relações.

Segundo Silva, Silva e Finco (2020), no Brasil, a primeira Orientação Educativa para educação e o cuidado das crianças em creches, período denominado Creche-Urgente, foi elaborada pelo Conselho Nacional dos direitos da Mulher - CNDM e pelo Conselho Estadual da Condição Feminina - CECF, sem qualquer influência ou interferência do MEC. Os autores, explicam também que o documento acima referido defendia a "creche enquanto extensão do direito universal à educação da criação de 0 a 6 anos" (p.7), enfatizando as desigualdades entre homens e mulheres (como a citação abaixo, num dos trechos que apresenta uma crítica feroz ao papel que é esperado da mulher na sociedade), desconsiderando que o espaço poderia transformar as relações no que se refere à interação adulto/a-criança, adulto/a-adulto/e criançacriança. Historicamente as mulheres eram diferenciadas dos homens por sua fragilidade e habilidades maternas, consideradas como dom divino, natural. Essa crença era reforçada pelo fato de poderem gerar a vida, estando à disposição para cuidar das crianças e do marido. $\mathrm{O}$ mesmo documento defende que a presença materna não é indispensável para que a criança cresça de forma saudável; denunciou que a sociedade não oferecia às mães, agora também profissionais que trabalham fora de casa, instituições viáveis para o bom desenvolvimento das crianças e as que existiam sofriam com a precariedade de influências assistencialistas, consideradas “mães precárias". Mostrou a creche não como mal necessário às mães que queriam trabalhar fora de casa, mas sim como uma instituição legalizada e própria para receber e iniciar a educação infantil.

Observamos então que a creche, após processo de luta e conquista social, é entendida como um direito da criança à educação. A instituição social escolar é um espaço no qual se vive diversas relações de poder, como: gênero, classe, idade e etnias. Apesar da inserção precoce da criança ao ambiente escolar, no que se refere à sua idade biológica, Ribeiro e Béssia (s/d) descrevem a família em sua obra como sendo a principal unidade básica de desenvolvimento do ser humano. É na instituição social família que o sujeito desenvolve suas primeiras habilidades e expressões de comportamento social. Portanto, compreende-se que a família 


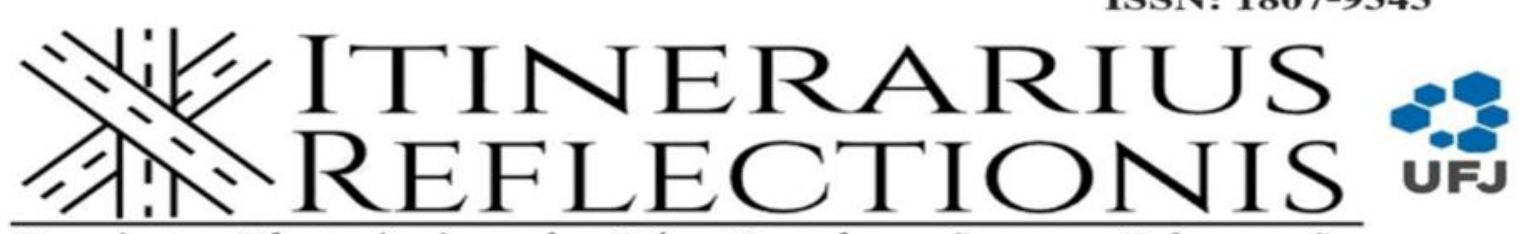

Revista Eletrônica da Pós-Graduação em Educação Universidade Federal de Jataí

Volume, 17, número 3, ano 2021

como base dessa sociedade assegure os direitos da criança para que ela seja inserida e se torne sujeito ativo desta. Em Silva, Nunes, Betti e Rios (2008), vamos encontrar o esclarecimento de que a criança, ao nascer, já encontra um mundo organizado, segundo parâmetros construídos pela sociedade como um todo, no qual sua família já está inserida e já possui sua cultura própria que, por sua vez, se apresenta carregada de valores, hábitos, mitos, formas de interpretar o mundo, e lhes possibilita diferentes maneiras de trocas intersubjetivas e, consequentemente, ajuda na construção da subjetividade.

Dessa forma, a participação dos pais na educação formal dos filhos deve ser constante e consciente, a vida familiar e a vida escolar devem ser simultâneas e complementares, as duas instituições devem se organizar na tentativa de alcançar o objetivo maior, que é a formação integral da criança. Conforme Silva et al. (2008), os recursos de mecanismo relevantes para o desenvolvimento escolar mudam conforme a criança se desenvolve, e a importância do envolvimento familiar, estimulação oferecida no lar e o comprometimento dos pais com a escolarização da criança são importantes desde a pré-escola até a universidade.

O desenvolvimento escolar nas diferentes etapas de ensino está diretamente ligado à organização do ambiente familiar, ao engajamento dos pais e às oportunidades que lhes são oferecidas no ambiente escolar. Em situação oposta, os autores descrevem alguns contextos sobre crianças que apresentam dificuldade no aprendizado escolar, que possuem uma história de vida marcada por adversidades, dentre elas, fatores como doença mental em um dos pais, desarmonia conjugal e modelos de comportamento desviante; enfatizam que o acúmulo dessas adversidades em contexto de pobreza, aumenta significativamente o risco para problemas na área da educação. Desse modo, fica nítido que circunstâncias familiares podem fragilizar a criança em seu aprendizado escolar.

No que se dispõe ao desenvolvimento escolar da criança, deve-se considerar aspectos relacionados à família, à escola e ao meio social, pois o aprendizado escolar não se apresenta isoladamente como uma questão pedagógica ou de capacidade individual, se faz necessário, por isso, avaliar e compreender o contexto em que a criança está inserida. Desse modo, podemos observar que o ambiente no qual as crianças convivem pode influenciar no seu aprendizado de uma forma negativa ou positiva. Silva et al. (2008) trazem em seus estudos fatores de risco que implicam o desenvolvimento infantil. Tais fatores podem estar relacionados à criança, à família 


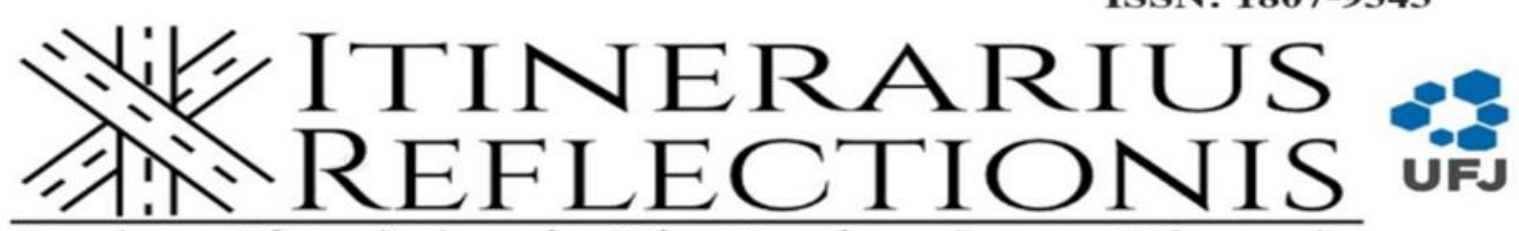

Revista Eletrônica da Pós-Graduação em Educação Universidade Federal de Jataí

Volume, 17, número 3, ano 2021

e ao ambiente e impedem ou dificultam a aprendizagem, a socialização e o desenvolvimento saudável da criança, acarretando, portanto, o aumento da probabilidade de ocorrências de resultados negativos.

Como fatores de risco os autores descrevem a história de desenvolvimento dos pais, sua personalidade, habilidades parentais, depressão parental, baixo nível educacional, altos níveis de estresse, doenças psiquiátricas, falta de apoio social, condições inadequadas de habitação, saúde, educação, alimentação. Em relação à criança, têm-se a idade, temperamento, déficits ou dificuldades neurofisiológicas, níveis subclínicos de transtorno de conduta, entre outros. Entretanto, destaca -se a pobreza como o fator de risco mais grave, pois esta pode acarretar e levar a vários outros fatores, inclusive de desestruturação familiar.

Portanto, é papel da família agir de modo ativo a essa construção orientando-a sobre assuntos relacionados ao seu cotidiano de modo a ensinar noções de solidariedade, entre outros, dando-lhes uma educação sadia e transmitindo afeto. Dentre os fatores que influenciam no desenvolvimento e aprendizagem da criança, muitas vezes está a ausência da família no acompanhamento desse processo, não atendendo às necessidades básicas da criança, como afeto, apego, desapego, segurança, disciplina, diálogo, dentre outras, que são fundamentais para a capacidade de aprender e de se relacionar. Fica evidente, portanto, que a participação da família na educação formal deve ser constante, assídua e consciente. A vida familiar e a vida escolar devem estar em sintonia e se complementarem.

\subsection{Família, infância, educação infantil e o trabalho de educador}

O perfil do profissional da Educação presente nas Diretrizes e Bases da Educação Brasileira se apresenta no Título VI, pelo qual entende-se que são considerados profissionais da educação escolar básica os professores habilitados para docência; os trabalhadores em educação portadores do diploma de pedagogia, habilitados em administração, planejamento, supervisão, inspeção e orientação educacional; profissionais graduados que tenham feito complementação pedagógica, conforme disposto pelo Conselho Nacional de Educação. Os fundamentos da formação dos profissionais da Educação são:

I - a presença de sólida formação básica, que propicie o conhecimento dos fundamentos científicos e sociais de suas competências de trabalho; 


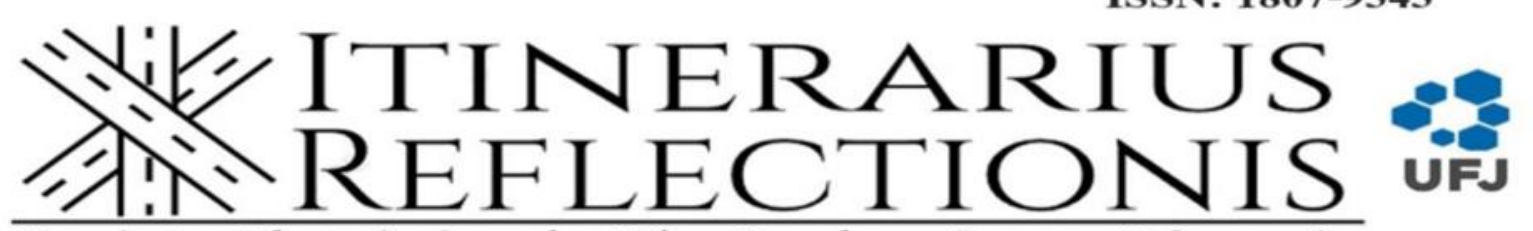

Revista Eletrônica da Pós-Graduação em Educação

Universidade Federal de Jataí

Volume, 17, número 3, ano 2021

II - a associação entre teorias e práticas, mediante estágios supervisionados e capacitação em serviço;

III - o aproveitamento da formação e experiências anteriores, em instituições de ensino e em outras atividades."

O artigo 62 da LDB transcreve que o docente deve ser formado em nível superior, licenciatura plena com formação mínima para o exercício do magistério.

No documento é apontado também que os institutos superiores de educação devem manter cursos formadores para os profissionais atuantes, programas de formação pedagógica para os docentes que queiram se dedicar à educação básica e programas de educação continuada. A formação docente incluirá prática de ensino de, no mínimo, trezentas horas. Na relação criança e Educação Infantil Silva, Silva e Finco (2020) apontam para o aspecto em relação à pequena infância e gênero na educação infantil, o que comprova um aumento significativo de pesquisas, publicações e eventos acadêmicos nesta área do conhecimento, tendo em vista a importância das instituições para a meta de construção de uma sociedade mais igualitária. A partir do estudo de Vianna e Finco (2009), constatamos que o direito a uma educação infantil de qualidade inclui a discussão das questões de gênero, pois nela não só se cuida do corpo da criança, mas também a educa. A educação infantil é o lugar, ao lado da família, em que se constroem com os pequenos, limites sociais e psicológicos. Assim, as imagens corporais são frutos de nossa cultura, portanto, uma construção social que se dá nas relações entre as crianças e entre estas e os adultos, de acordo com cada sociedade e cada cultura em que estão inseridas.

A Educação Infantil é provavelmente a etapa da educação em que existe ou deveria existir, o maior laço entre o aluno e sua família, é o momento das descobertas, em que a criança inicia sua vida na escola, deixa de usar fraldas, introduz a alimentação de forma independente. É um período em que a criança constrói noções de identidade e independência. Muitas vezes, no quadro profissional da Educação Infantil, há predominância da presença de mulheres, principalmente por ser atribuído seu trabalho ao cuidar materno, fator que leva as mulheres a se identificarem com a pedagogia, afastando o gênero masculino da mesma.

De acordo com os estudos de Ramos, Oliveira e Silva (2019), o gênero nas profissões ainda é uma questão a ser trabalhada. Os autores esclarecem que muitas vezes, a mulher acaba sendo discriminada em certos empregos, com salários menores e cargos inferiores aos homens, contudo neste caso é o oposto. $\mathrm{O}$ gênero masculino na área da educação, principalmente em se 


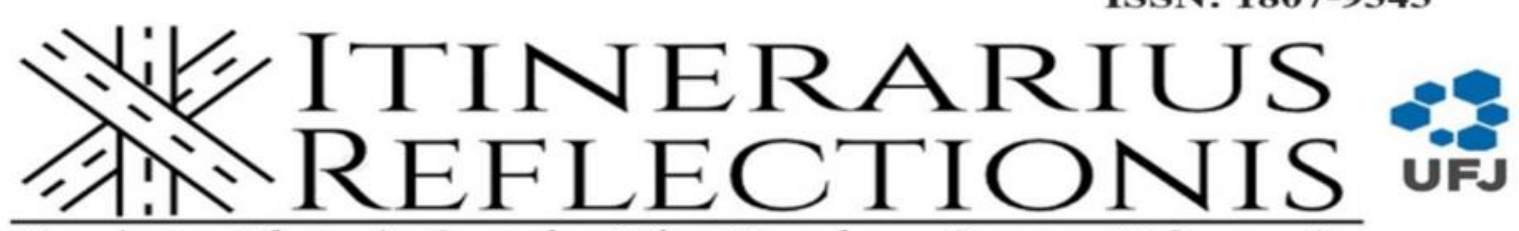

Revista Eletrônica da Pós-Graduação em Educação Universidade Federal de Jataí

Volume, 17, número 3, ano 2021

tratando de educação infantil, é julgado e certas vezes não aceito. Isso pode ser explicado por diversos motivos, seja por falta de confiança das famílias, devido aos inúmeros casos de estupro e abuso que são vividos por menores, onde o maior número das denúncias é contra homens, mas também pela história que, toma a maternidade como base para justificar o fato de a mulher ser mais indicada para lidar com crianças menores.

Esse fato se confirma através dos estudos de Gonçalves, Faria e Reis (2016), que pesquisam sobre os homens na educação infantil, conquistas e preconceitos, no intuito de identificar as representações sociais e as questões de gênero entre os homens que trabalham como professores com crianças de 0 a 5 anos de idade, matriculadas em instituições públicas de educação infantil, e a questão da limitação do homem quanto à sua atividade, uma vez que não lhes é permitido a execução de tarefas próprias da profissão, como banho e troca de fraldas, pois o receio da pedofilia é evidente.

Rodrigues (2008) e Gonçalves et.al. (2016) apontam para a importância do papel do professor homem tanto para a formação intelectual como social das crianças. Evidenciam que a educação infantil deve oferecer às crianças contato com adultos, que são as suas referências, de ambos os sexos, especialmente na escola, local em que elas iniciam a socialização fora da família, podendo-se afirmar, com isso, que homens podem, sim, contribuir de forma positiva com o processo de educação escolar de crianças. Portanto, se o homem é visto como pedagogo e está disposto a levar suas práticas para redimensionar conceitos e estereótipos, ele consequentemente questionará mais sobre seu papel na escola e na sociedade, construindo um espaço de mudança de visão da pedagogia, surgindo a necessidade de um diálogo sobre gênero na escola por meio da defesa de sua atuação na educação.

\section{CONSIDERAÇÕES FINAIS}

Com base no que foi exposto, por meio de alcance bibliográfico, podemos observar que o conceito família foi se ajustando à medida que as transformações sociais foram acontecendo, exigindo do legislador um posicionamento no que tange a tal fato. A família que compreendia uma concepção tradicional e monopolizada, estando relacionada apenas a núcleos ligados a enlaces sanguíneos, por meio de matrimônio, com vertente econômica patrimonial e de 


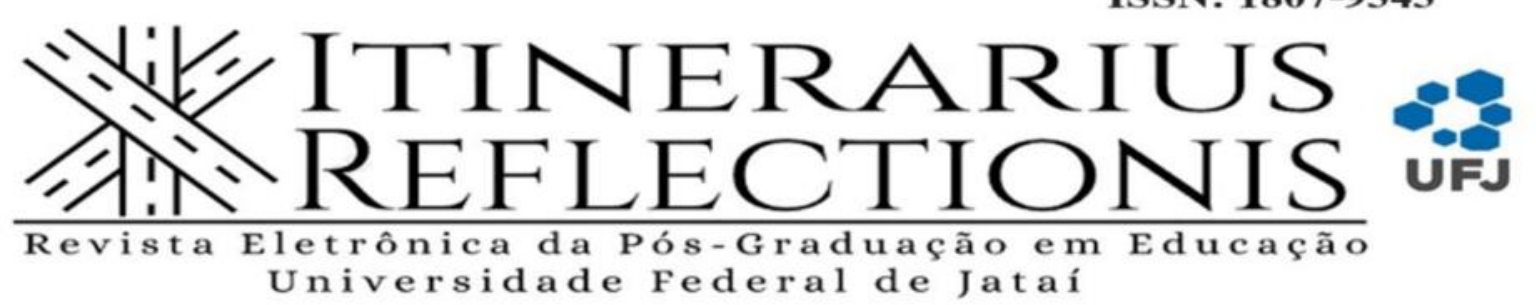

Volume, 17, número 3, ano 2021

reprodução, passou a abarcar toda sua pluralidade, passando a se constituir sob a vertente afetiva, embalada por princípios de ordem constitucional.

Por outro lado, podemos compreender a infância como condição social do ser criança, portanto, sofrendo variações conceituais que dependem do contexto social e cultural. A forma como concebem a infância traz implicações políticas, científicas e sociais na vida cotidiana, nas concepções de educação e na condição dos profissionais que estão destinados a cuidar delas e educá-las. Diante da pluralidade familiar, decorrente do contexto histórico e social, fica evidente que, além da análise da família como contexto de desenvolvimento da criança, e ser considerada um fenômeno complexo, a fase de desenvolvimento escolar da criança, mais especificamente, evidencia a importância da família no processo educativo, contribuindo ou prejudicando a adaptação dela a esse contexto. Em relação à educação infantil, compreendemos que existe um preconceito cultural e social que dificulta o ingresso e permanência do homem na profissão de pedagogo, mais especificamente como professor na educação infantil. Entretanto, acreditamos que a atuação de pedagogos conscientes deve contribuir para que esse preconceito diminua. Pesquisas sobre a atuação de trabalhadores masculino na educação infantil na intersecção com a diversidade de formações familiares é um interessante caminho a ser percorrido em futuras pesquisas.

\section{REFERÊNCIAS BIBLIOGRÁFICAS}

BRASIL. Supremo Tribunal Federal. Ação Direta de Inconstitucionalidade n. 1.627 - União Federal. Relator: Ministra Cármen Lúcia, Brasília, DF, julgado em: 18/08/2016. Disponívelem:https://redir.stf.jus.br/paginadorpub/paginador.jsp?docTP=TP\&docID=120218 64. Acesso em: 10/08/2021.

BRASIL. Estatuto da Criança e do Adolescente (versão 2019). Lei n8,069, de 13 de julho de 1990. Disponível em: https://www.gov.br/mdh/pt-br/centrais-de-conteudo/crianca-eadolescente/estatuto-da-crianca-e-do-adolescente-versao-2019.pdf. Acesso em: 10/08/2021.

BRASIL. Base Nacional Comum Curricular (BNCC). 2017

BRASIL, Constituição da República Federativa do Brasil, 1988

BRASIL, Lei de Diretrizes e Bases da Educação Nacional - LDB, 1996

DURKHEIM, E. Educação e sociologia. São Paulo: Melhoramentos, 1978. 


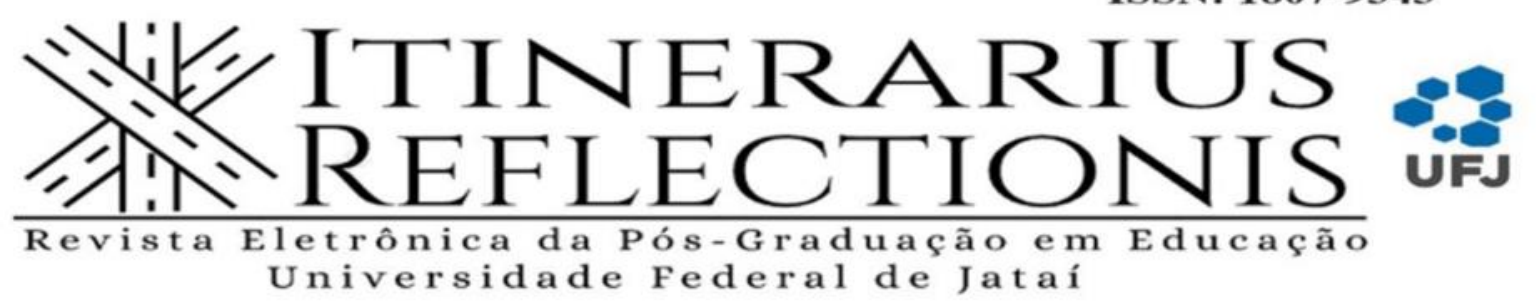

Volume, 17, número 3, ano 2021

GONÇALVES, Josiane Peres; FARIA, Adriana Horta de; REIS, Maria das Graças Fernandes de Amorim dos. Olhares de professores homens de Educação Infantil: Conquistas e preconceitos. Florianópolis: Perspectiva, 2016.

LINHARES, Francisco Reginaldo; MACEDO, Sheyla Maria Fontenele. O PedagogoProfessor na Educação Infantil: desafios na relação teoria e prática do cuidar e educar, 2012.

LINS, Samuel Lincoln Bezerra; SILVA, Maria de Fátima Oliveira Coutinho da; LINS, Zoraide Margaret Bezerra; CARNEIRO, Terezinha Féres. A compreensão da infância como construção sócio-histórica, 2014.

LOBATO, Vivian da Silva; SANTOS, Graciete Costa dos. Subsídios Teóricos e reflexões sobre a relação família-escola no contexto educacional brasileiro, s/d.

NASCIMENTO, Claudia Terra do; BRANCHER, Vantoir Roberto; OLIVEIRA, Valeska Fortes de. A Construção social do conceito de infância: algumas interlocuções históricas e sociológicas, 2008.

NASCIMENTO, Arlindo Mello do. População e família brasileira: ontem e hoje, 2006.

NORONHA, Maressa Maelly Soares; PARRON, Stênio Ferreira. A evolução do conceito de família, 2017.

RAMOS, Gabriela Duarte Camaño; OLIVEIRA, Luana Maria Miranda de; SILVA, Sandra Maria Bezerra da. A presença do profissional do sexo masculino na educação infantil, 2019.

RODRIGUES, Diego Pires. Paradigmas do homem na pedagogia: A atuação do pedagogo como fonte de transformação, 2008.

ROUSSEAU, Jean-Jcques. Emilio ou da educação. $3^{\mathrm{a}}$ ed., Rio de Janeiro: Bertrand Brasil, 1995.

SILVA, Nancy Capretz Batista da; NUNES, Célia Cristina; BETTI, Michelle Cristine Mazzeto, RIOS, Karyne de Souza Augusto. Variáveis da família e seu impacto sobre o desenvolvimento infantil, 2008.

SILVA, Peterson Rigato da; SILVA, Tassio José da; FINCO, Daniela. Relações de gênero, educação da pequena infância e mudanças políticas no Brasil: contribuições para um, estado da arte, 2020.

VIANNA, Claudia; FINCO, Daniela. Meninas e meninos na educação infantil: Uma questão de gênero e poder, 2009. 